\title{
Relação entre a qualidade da água e o uso do solo em microbacias do reservatório Billings, na Região Metropolitana de São Paulo - SP
}

Water quality and land use relations on Billings Reservoir watershed, Metropolitan Area of São Paulo, Brazil
Submetido em: 15/08/17 Revisado em: 07/02/18 Aprovado em: 05/04/18

\section{Paula Lopes de Araujo \\ Diana Sarita Hamburger \\ Tatiane Araujo de Jesus \\ Roseli Frederigi Benassi \\ Valdir de Cicco}

\section{RESUMO}

Atividades humanas demandam certos níveis de qualidade da água, no entanto, seus subprodutos a afetam por poluição. Este trabalho objetivou entender a poluição de bacias tributárias por meio da análise de parâmetros de qualidade da água e sua correlação com o uso e a ocupaçáo do solo em microbacias do reservatório Billings na Região Metropolitana de São Paulo (RMSP). Utilizaram-se os parâmetros: Temperatura da água, Turbidez, $\mathrm{pH}$, Oxigênio Dissolvido, Sólidos Totais Dissolvidos, Condutividade Elétrica e Fósforo Total. Os valores foram comparados com a Resolução CONAMA $357 / 2005$. Foi proposto um agrupamento das classes de uso do solo conforme o grau de antropização, por meio de Sistema de Informação Geográfica (SIG). Os resultados mostraram correlaçóes significativas entre os parâmetros de qualidade e o uso e a ocupação do solo. Locais mais antropizados foram responsáveis por uma maior degradação da qualidade da água para os parâmetros: Turbidez, Sólidos Totais Dissolvidos, Condutividade Elétrica e Fósforo Total. Alguns valores para as zonas de influência antrópica apresentaram desacordo com os parâmetros estabelecidos pela resolução CONAMA 357/2005. O estudo demonstrou a importância da preservação da vegetação em áreas de mananciais a fim de contribuir com a qualidade das águas.

Palavras-chave: Recursos Hídricos; Qualidade da Água; Uso do solo; Microbacias; Geoprocessamento

\section{ABSTRACT}

Human activities demand certain levels of water quality. However, its by-products affect it by pollution. This work aimed to understand the pollution of tributaries basins by analysis of water quality parameters and their correlation with the land use and occupation in micro catchments of the Billings Reservoir in the Metropolitan Area of São Paulo (MASP). The parameters were: Water temperature, Turbidity, pH, Dissolved Oxygen, Total Dissolved Solids, Electrical Conductivity and Total Phosphorus. The values were compared with CONAMA Resolution 357/2005. A grouping of land use classes was proposed according to the degree of anthropization using Geographic Information System (GIS). Results showed significant correlations between water quality parameters and land use and occupation. More anthropogenic sites were responsible for a greater degradation of water quality for the parameters: turbidity, total dissolved solids, electrical conductivity and total phosphorus. Areas more influenced by human activities showed disagreements with the parameters established by CONAMA Resolution $357 / 2005$. The study demonstrated the importance of preserving vegetation in water source areas in order to contribute to water quality.

Keywords: Water resources; Water Quality; Land Use; Micro Watersheds; Geoprocessing

\section{INTRODUÇÃO}

O avanço da urbanização sobre áreas naturais eleva o risco de escassez de água, devido ao aumento da demanda por recursos hídricos e a redução na oferta, por meio de alteraçóes no ciclo hidrológico.
As diversas atividades humanas traduzem-se em diferentes formas de uso do solo que interferem no ambiente, principalmente pelo consumo de recursos e lançamento de resíduos. No caso de regióes metropolitanas, o risco de escassez de água é mais acentuado, tendo em vista a quantidade de pessoas e o seu padrão 
de uso e cobertura do solo, com influência direta na qualidade da água.

A unidade espacial de estudos dos recursos hídricos é a bacia hidrográfica, preconizada como unidade de planejamento pela Política Nacional de Recursos Hídricos, Lei no 9433 de 1997 (BRASIL, 1997). A delimitação destas bacias deve considerar as elevaçóes interfluviais, seguindo os pontos cotados e as curvas de nível (HORTON, 1945). Bacias hidrográficas podem ser subdivididas em bacias menores, tal qual uma microbacia, a menor unidade geomorfológica da paisagem que permite quantificar o funcionamento da natureza de forma integrada, manifestando-se como um sistema natural aberto (LIMA e ZAKIA, 1998). As atividades desenvolvidas dentro dessa unidade influenciam tanto em aspectos hidrológicos como biogeoquímicos, afetando, por exemplo, a qualidade e a quantidade de água.

Entender influências do uso e cobertura do solo sobre corpos hídricos é alvo de estudos recentes (MENEZES et al., 2016; SILVA et al., 2011; SOUZA e GASTALDINI, 2014). O impacto do uso do solo na qualidade de pequenos arroios tem ganhado interesse de vários estudos em pequenas bacias hidrográficas, como, por exemplo, os estudos de Fernandes et al. (2011), na microbacia Glória, Macaé - RJ; Coelho et al. (2011) estudando microbacias de 0,2 a $6 \mathrm{~km}^{2}$ do rio Caí e dos arroios Caçador e Tiririca, no município de Canela - RS.

Assim, o presente trabalho avaliou a qualidade da água em 6 microbacias submetidas a variados usos e ocupação do solo, cuja drenagem verte para o reservatório Billings. Os valores foram comparados com a tabela do atendimento aos padróes de enquadramento conforme a legislação pertinente. Objetivou-se auxiliar o entendimento da poluição de bacias tributárias através de uma proposta de ranqueamento pelo grau de antropização do uso do solo e sua correlação com parâmetros de qualidade da água em microbacias.

\section{METODOLOGIA E ÁREA DE ESTUDO}

A área de estudo é compreendida por microbacias entre 0,07 e $0,26 \mathrm{~km}^{2}$ situadas na bacia do Alto - Tietê, sub-bacia Billings-Tamanduateí, no município de São Bernardo do Campo, integrante da Região Metropolitana de São Paulo - RMSP. Conforme dados do
Sistema Nacional de Informaçóes sobre Saneamento, o índice de tratamento do esgoto coletado na RMSP é de 47,5\% (SNIS, 2014). A bacia hidrográfica do reservatório Billings ocupa um território de 582,8 $\mathrm{km}^{2}$, cuja área de drenagem abrange os municípios de Rio Grande da Serra, Diadema, Ribeirão Pires, Santo André, São Bernardo do Campo e São Paulo e está inserida no domínio da Mata Atlântica (ISA, 2002). Devido ao seu formato dendrítico, o reservatório está dividido em sub-regióes de acordo com seus braços. A área de estudo está localizada entre as coordenadas UTM (zona 23) 7371174 e 7369150 N, 344759 e 348111 S (Figura 1). Os córregos das microbacias vertem para o Braço Rio Grande do reservatório Billings, local de captação de água para abastecimento público pela Companhia de Saneamento Básico do Estado de São Paulo - Sabesp.

Em relação ao clima, segundo a classificação de Koeppen, o tipo dominante na região é o Cwa, caracterizado pelo clima tropical de altitude, com predominância de chuvas no veráo e períodos mais secos no inverno, com a temperatura média no mês mais quente superior a $22^{\circ} \mathrm{C}$ (CEPAGRI e UNICAMP, s.d.). No município de São Bernardo do Campo a temperatura média anual é de $20^{\circ} \mathrm{C}$ e a pluviosidade média anual é de 111 milímetros, com período seco entre os meses de abril e setembro e chuvoso entre outubro e março (EMBRAPA e ESALQ, 2003).

Dados de chuvas acumuladas das 24 horas anteriores à coleta, bem como o acumulado mensal foram obtidos no portal do Centro Nacional de Monitoramento e Alertas de Desastres Naturais - CEMADEN.

Para a delimitação das microbacias hidrográficas e rede hídrica, foram utilizadas cartas planialtimétricas da RMSP na escala 1:10.000, produzidas nos anos 1980/1981 pela Empresa Paulista de Planejamento Metropolitano S.A (SCM/EMPLASA). Empregaram-se as articulaçóes do Sistema Cartográfico Metropolitano, folhas Riacho Grande (articulação 3222) e Caveiras (articulação 4211). Os cursos d'água de primeira ordem foram digitalizados e caracterizados como tributários diretos de um corpo hídrico (HORTON, 1945). Considerou-se como microbacias hidrográficas a área de contribuição da drenagem com afluxo para os cursos d'água de primeira ordem, a partir das curvas de nível e cotas altimétricas das cartas. 
Figura 1- Área de estudo. Destaque para as microbacias avaliadas, Bacia da Billings, São Bernardo do Campo - SP

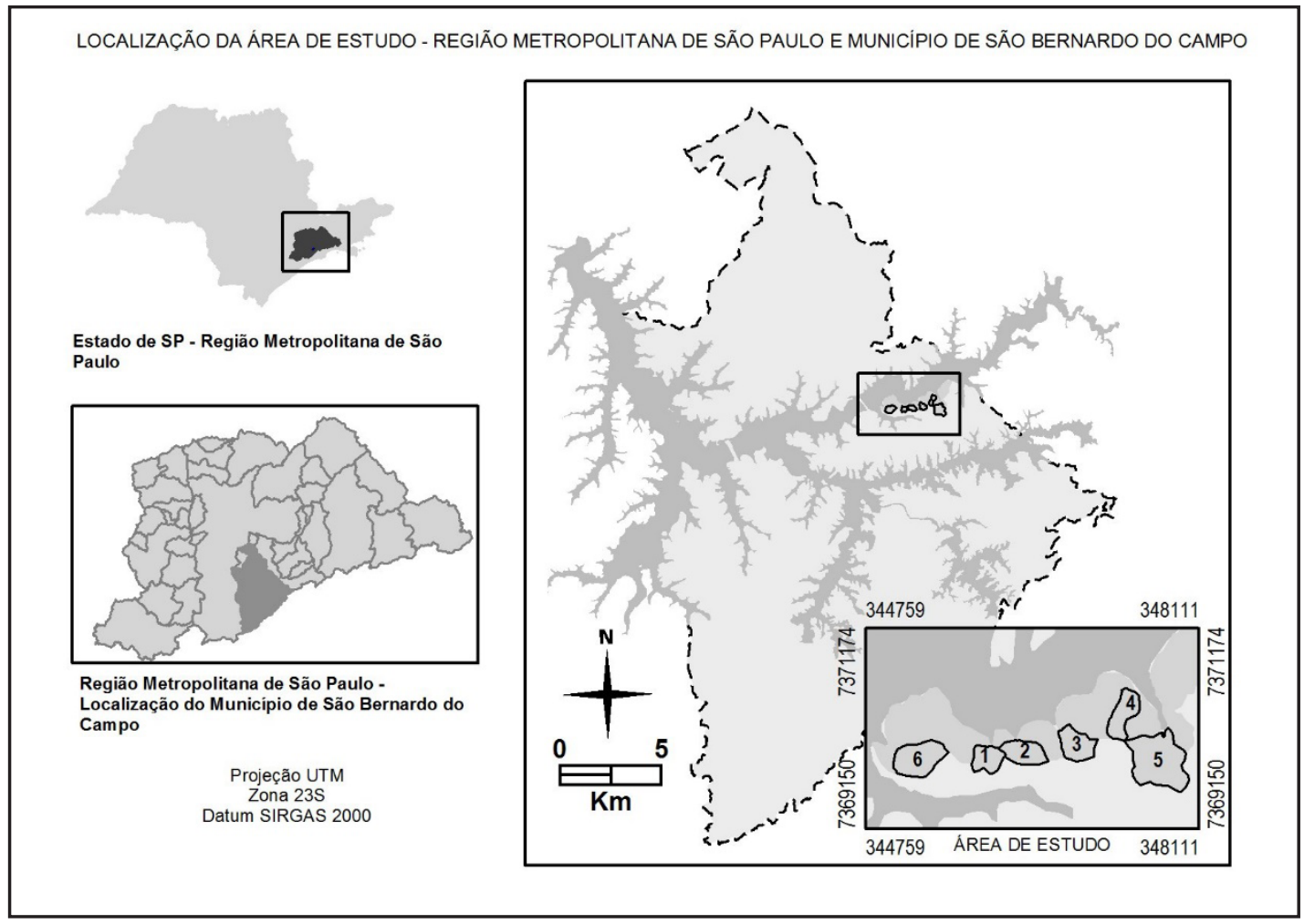

Foi utilizado mapa de uso do solo fornecido pela Prefeitura de São Bernardo do Campo, o qual foi gerado a partir de imagens do satélite WorldView-2 da DigitalGlobe, com resoluçáo espacial de $0,5 \mathrm{~m}$, para o ano de 2011, em escala 1:2.000. O mapa de uso e cobertura do solo foi comparado a imagens de satélites atualizadas para o ano de 2016, através do Google Earth ${ }^{\oplus}$. Verificou-se, de forma visual, que não houve alteraçóes de uso e cobertura do solo no período avaliado. O uso do solo nas microbacias foi analisado em ambiente de Sistema de Informaçóes Geográficas (SIG) - Geomedia ${ }^{\circledR}$ Professional 2014. As classes de uso do solo seguiram as descriçóes conforme o Atlas de Uso e Ocupação do Solo da RMSP (EMPLASA, 2003).

Dados de esgotamento sanitário por domicílio foram obtidos a partir do Censo Demográfico de 2010 do Instituto Brasileiro de Geografia e Estatística (IBGE). Os setores censitários referentes às microbacias da área de estudo foram analisados para verificar a existência de domicílios com lançamento de esgotos sem tratamento nos corpos hídricos.

Para o monitoramento da qualidade da água foram realizadas cinco campanhas de amostragem, no período matutino, nas seguintes datas: 30/04/2015, 30/06/2015, 28/08/2015, 28/10/2015 e 02/03/2016. As amostragens foram realizadas a jusante dos córregos, recomendado para melhor avaliar a contribuição do uso a montante sobre o corpo hídrico (CETESB e ANA 2011). Foram determinados in situ os parâmetros: temperatura da água, turbidez, $\mathrm{pH}$, oxigênio dissolvido (OD), sólidos totais dissolvidos (STD) e condutividade elétrica (CE) por meio de sonda multiparamétrica, marca Hanna, modelo HI 9829, previamente calibrada. Coletas de amostras de água foram realizadas em triplicata, acondicionadas em caixas térmicas refrigeradas e transportadas ao Laboratório de Análises Ambientais da UFABC, em Santo André - SP, para a determinação das concentraçôes de fósforo total (PT). Para estas determinaçóes foi 
empregada digestão com reagente oxidante conforme método de Valderrama (1981) e, posteriormente, o método colorimétrico com ácido ascórbico conforme Strickland e Parsons (1960), com leitura em espectrofotômetro da marca Hach modelo DR 5000 a 880 nm e correlação por meio de curva de calibração previamente preparada.

As estaçóes monitoradas correspondem a locais com variabilidade de uso e cobertura do solo, conforme a Figura 2, o que permite a avaliação de possíveis influências sobre a qualidade da água. A estação 1 refere-se a um córrego com predominância de mata na microbacia. A estação 2 possui mata em seu entorno, além de mancha de reflorestamento de eucalipto, sem manejo de silvicultura aparente conforme verificado nas campanhas de campo. A estação 3 está localizada em área com residências esparsas e chácaras. A estação 4 refere-se a um córrego localizado em um clube, com presença de vegetação baixa (gramíneas). A estação 5 visou verificar a influência de área com horticultura, no entanto, o córrego constante na carta do SCM/ EMPLASA não foi localizado em campo, de modo que a coleta ocorreu na represa, o mais próximo da vertente. Por se tratar de um braço mais isolado da represa, espera-se que as características da água nesta área sofram menor e mais lenta mistura com o restante da represa. A estação 6 buscou monitorar um córrego localizado em área com ocupação humana intensa e presença de urbanização precária. As mediçóes nesta estação ocorreram a partir da segunda campanha de campo, em 30/06/2015. As coordenadas geográficas das estaçóes de coleta constam na Tabela 1.

Tabela 1 - Coordenadas geográficas das estaçóes de coleta (UTM - Zona 23 S)

\begin{tabular}{l|c|c}
\hline Estaçóes & Latitude & Longitude \\
\hline 1 & 7369918 & 345953 \\
\hline 2 & 7369949 & 346232 \\
\hline 3 & 7369987 & 346765 \\
\hline 4 & 7370459 & 347412 \\
\hline 5 & 7370095 & 347739 \\
\hline 6 & 7369825 & 345075 \\
\hline
\end{tabular}

Figura 2 - Uso e ocupação do solo nas microbacias e localização das estaçóes de monitoramento

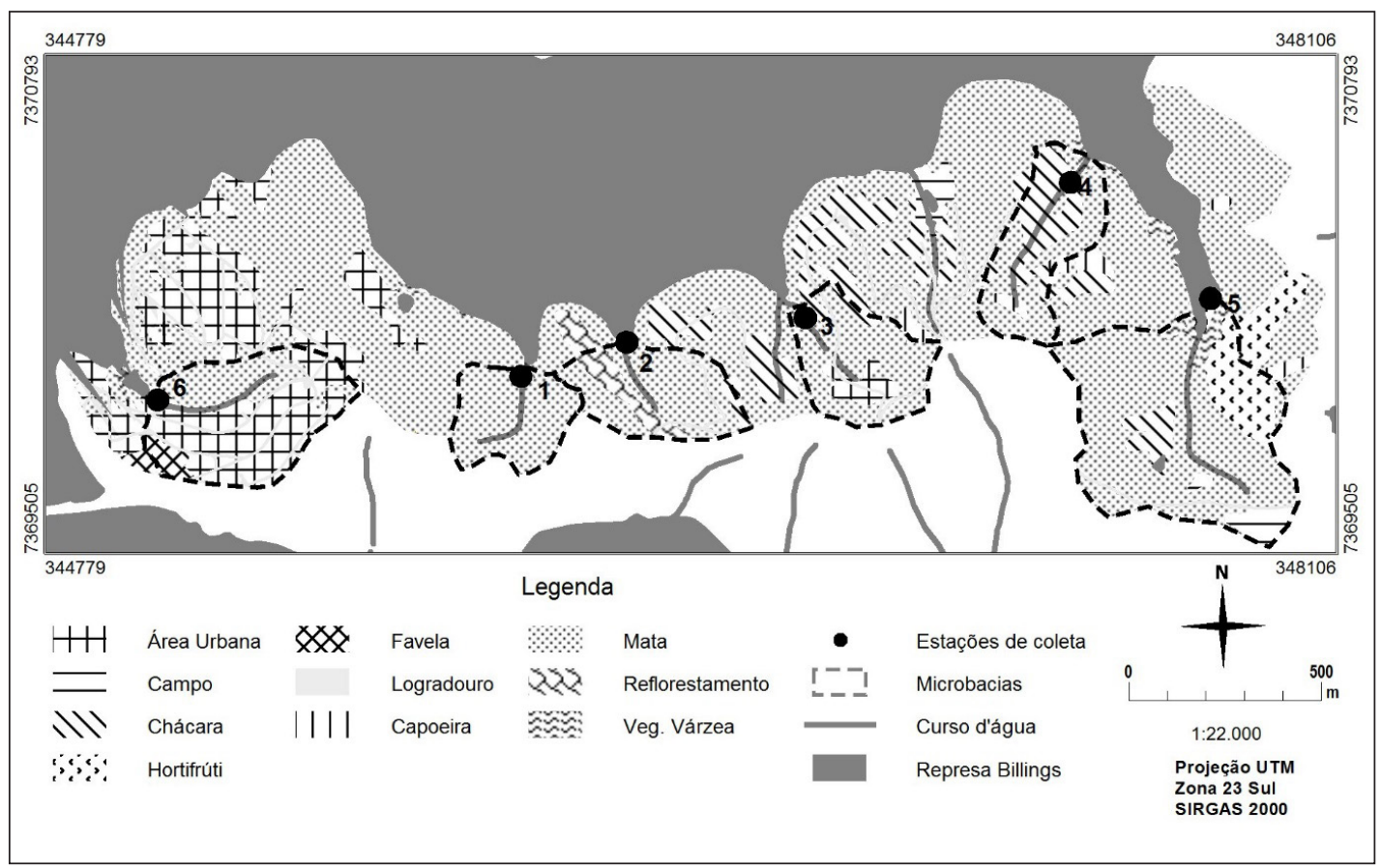


Para analisar a correlação entre os parâmetros de qualidade da água e o uso do solo, Ometo et al. (2000) recomendam a adoção de uma escala para agrupar as classes de uso e cobertura do solo conforme seu potencial poluidor. No presente estudo foram adotados três grupos de classes de uso do solo: (1) mata; (2) usos moderadamente antropizados (usos rurais como chácaras e horticultura); e (3) usos fortemente antropizados (áreas urbanizadas e favelas).

A verificação do atendimento à legislação vigente ocorreu por comparação dos resultados dos parâmetros mediante os padróes requeridos pela Resolução CONAMA 357/2005 (BRASIL, 2005), conforme o enquadramento em classes definido pelo Decreto Estadual no 10.755/1977 (SÃO PAULO, 1977), o qual define que tributários do braço do Rio Grande da Represa Billings enquadram-se na Classe 2. Os parâmetros temperatura da água e condutividade elétrica não puderam ser comparados, dado que não possuem padróes definidos por essa Resolução.

A fim de avaliar a distribuição dos dados, foi aplicado o Teste de Normalidade Shapiro-Wilk a um nível de significância de 0,05 para os parâmetros, considerando dados com distribuição Normal com p > 0,05.

Para verificação de possível influência da pluviosidade sobre os parâmetros de qualidade da água, bem como do uso do solo sobre os mesmos, foram utilizadas as ferramentas estatísticas do Microsoft Excel $^{\circledR}$ : cálculo do coeficiente de correlação de Spearman, e a verificação da significância da correlação por meio do teste de hipótese t de Student, recomendado para amostras menores que 30 (LAPPONI, 2005), a um nível de significância $\alpha$ de 0,05 com $\mathrm{n}-2$ graus de liberdade (GINEVAN, 2004).

Para comparação dos parâmetros de qualidade da água entre as diferentes estaçôes de amostragem foi utilizado o teste não paramétrico de Kruskal-Wallis, pelo qual é possível verificar se há diferença significativa entre os resultados dos parâmetros e os diferentes pontos de monitoramento. Foi adotado o nível de significância de $5 \%$ para os testes. Também foi realizado teste post hoc de Dunn com a finalidade de identificar se existe diferença estatística entre os pontos avaliados para os parâmetros de qualidade da água e análise de Cluster para confirmar o grau de similaridade entre as áreas analisadas, por meio do programa estatístico Past versão 3.19 (HAMER, 2018).
A variabilidade dos resultados dos parâmetros em cada estação é apresentada em gráficos do tipo Box Plot, com tendência e dispersáo central, amplitude dos valores e simetria (GINEVAN, 2004).

\section{RESULTADOS E DISCUSSÃO}

As classes predominantes de uso do solo em cada uma das microbacias estão representadas na Figura 3. Foram consideradas predominantes as três maiores classes de uso e ocupação do solo que, somadas, resultam em mais de $80 \%$ do uso e cobertura do solo na microbacia.

Todas as microbacias apresentaram, em maior ou menor proporção, uma porcentagem de mata entre as classes de uso e cobertura predominantes. A maior proporçáo de mata refere-se à estaçáo 1 , correspondendo a mais de $90 \%$ da área da microbacia. A microbacia com menor proporção de mata é a estação 6 , a qual também apresentou a maior proporção de área urbanizada, com mais de $50 \%$, além de favela, com 5 $\%$ da área. Também foi identificada área urbanizada na microbacia da estaçáo 3 com 11,84\%. A classe de uso e cobertura do tipo "chácaras" foi encontrada nas microbacias das estaçóes 2, 3, 5 e, em maior proporção, na estação 4 . A classe "hortifrúti" apenas foi identificada na estaçáo 5 , correspondendo a 12,92\% da área da microbacia.

Quanto ao esgotamento sanitário, as microbacias das estaçóes 3, 4 e 5 estão contidas dentro do mesmo setor censitário. Conforme dados do censo IBGE de 2010, o total da população residente nesse setor era de 600 habitantes, com 309 domicílios, dos quais 224 possuíam lançamento de esgoto a céu aberto, ou seja, mais de $70 \%$ dos domicílios. A microbacia da estaçáo 1 está contida em um grande setor censitário, com 353 domicílios, dos quais 322 não possuíam coleta ou tratamento de esgotos em 2010. A microbacia da estação 6 está contida em dois setores censitários, com o total de 1482 pessoas em 732 domicílios, para os quais o índice de lançamento de esgoto a céu aberto era superior a $90 \%$. Tais resultados apontam para a influência do despejo de esgotos domésticos sem tratamento nos córregos, podendo afetar os parâmetros de qualidade da água, principalmente nos locais com maior concentração de assentamentos humanos. 
Figura 3 - Distribuição das classes de uso (\%) do solo nas seis microbacias monitoradas

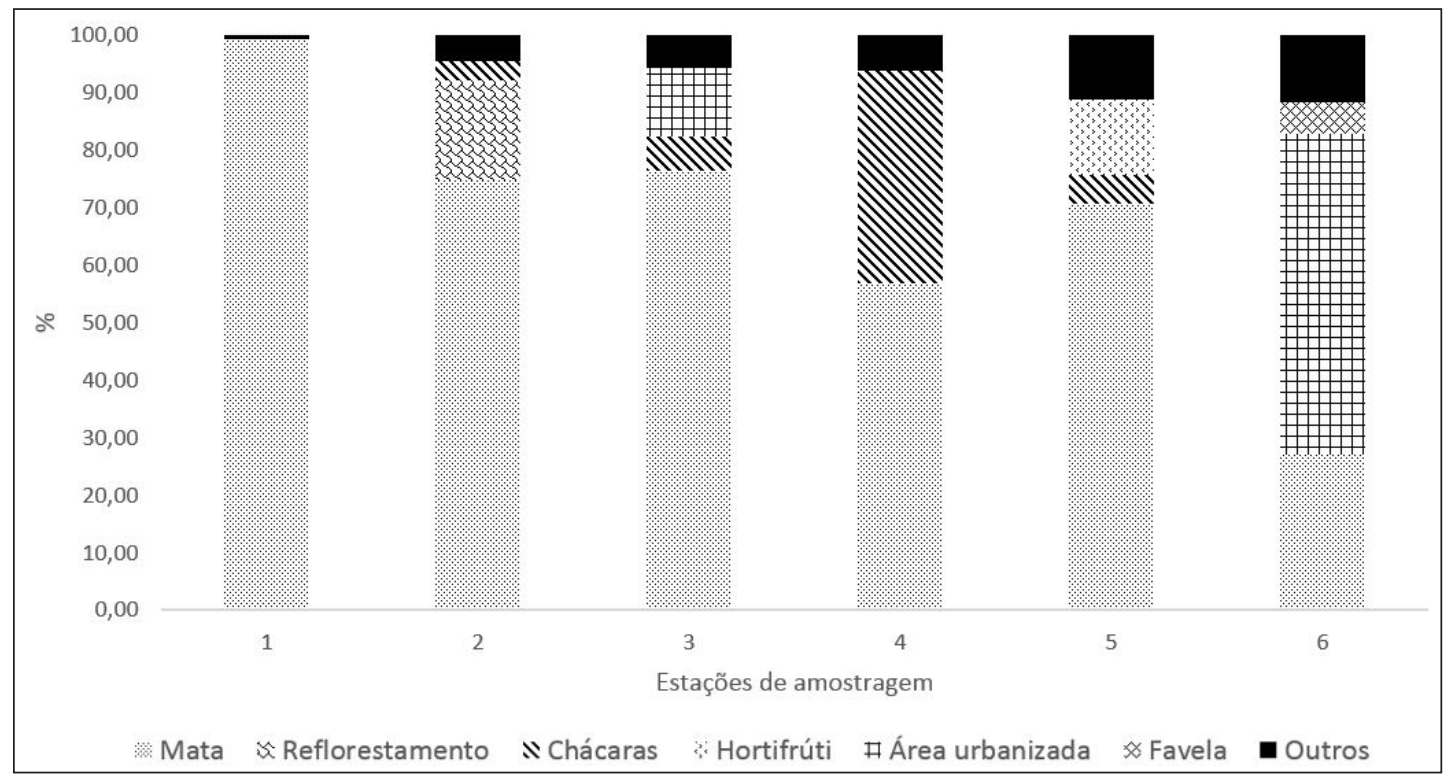

Verificou-se, por meio da análise de Cluster (Figura 4), que as seguintes microbacias apresentaram mais semelhanças nos resultados dos parâmetros: microbacias 1 e 2 (com maiores proporçóes de mata); microbacias 3 e 6 (mais uso urbano); microbacias 4 e 5 (usos mais rurais).

Figura 4 - Análise de Cluster para os dados de qualidade de água das microbacias da Represa Billings, São Bernardo do Campo, SP

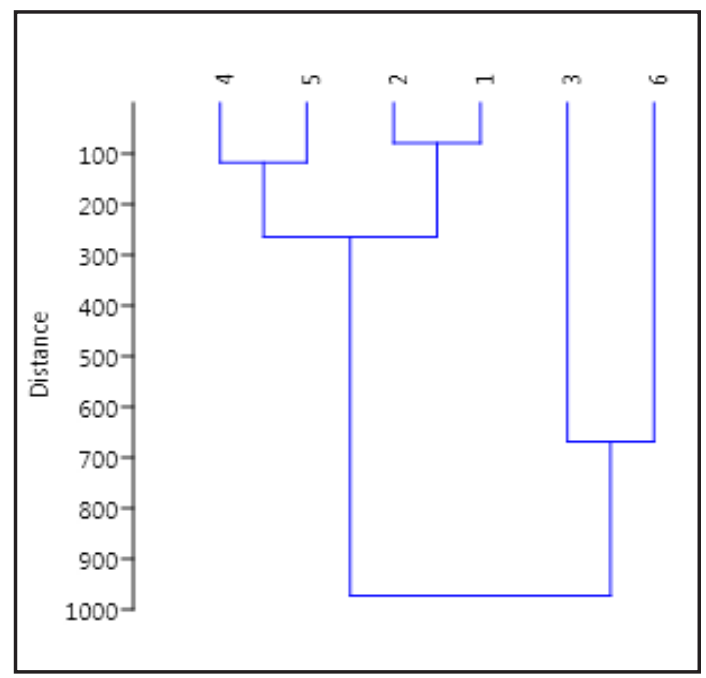

Os resultados dos parâmetros de qualidade da água são apresentados por meio de gráficos do tipo Box plot (Figura 5). A temperatura da água manteve-se dentro da faixa dos $17^{\circ} \mathrm{C}$ e $25^{\circ} \mathrm{C}$, sendo que as estaçóes 5 e 6 apresentaram valores mais elevados, o que pode ser, em parte, explicado pela maior incidência de radiação solar, pois estes locais eram os últimos coletados e encontram-se em área mais aberta, sem vegetação ciliar.

Os valores de $\mathrm{pH}$ apresentaram-se majoritariamente na faixa da neutralidade, ou seja, próximo a 7 . Entretanto, pode-se observar na Figura 5 que as estaçóes 1 e 2 apresentaram os menores valores de $\mathrm{pH}$ (apresentando mínimas abaixo de 5,0 e média abaixo de 7,0), caracterizando-as como ambientes ligeiramente ácidos. Tal fato pode estar atrelado à presença natural de matéria orgânica oriunda da vegetação no entorno, a qual pode contribuir com a redução do pH (FUNASA, 2014). Observam-se valores mais elevados de $\mathrm{pH}$ na estação 6 (mínima acima de 6,0, máxima acima de 9,0 e valores médios acima de 7,0), que pode estar relacionado a despejos de efluentes, caracterizando-se como um dos fatores antropogênicos que podem alterar o $\mathrm{pH}$ da água (VON SPERLING, 2005).

Foram identificados padróes semelhantes entre as estaçôes para os parâmetros turbidez, condutividade 
Figura 5 - Gráficos Box plot dos resultados dos parâmetros de qualidade de água nas seis estaçóes de amostragem

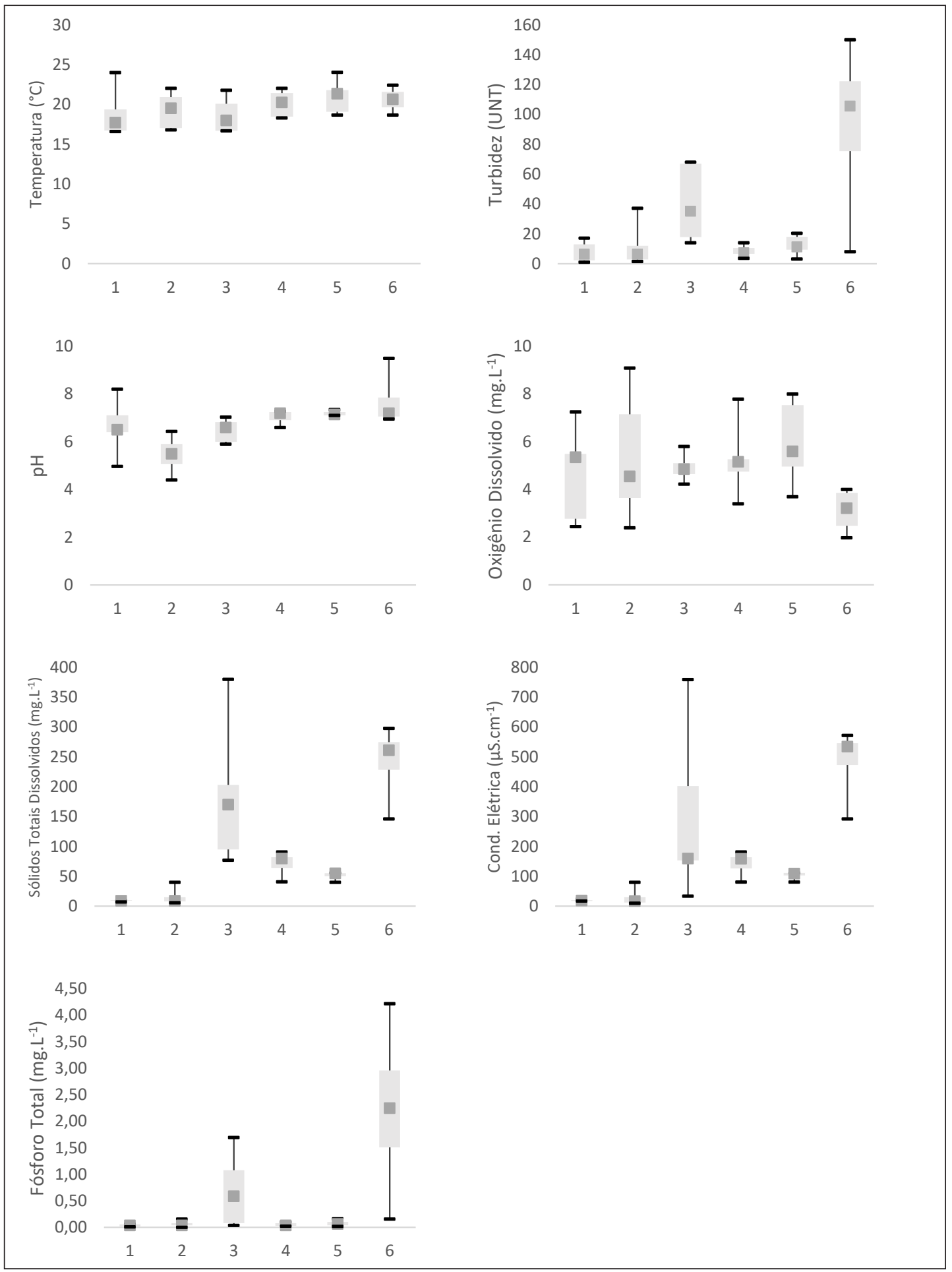


elétrica e sólidos totais dissolvidos. Verificou-se que os menores teores foram obtidos nas estaçóes $1 \mathrm{e}$ 2 , correspondentes aos usos menos antropizados e com predominância de vegetação (do tipo "mata") que influencia na proteção do solo, reduzindo o aporte de partículas aos cursos d'água. Teores mais elevados foram observados nas estaçóes 3 e 6 , que possuem maior grau de antropização e também contribuição de efluentes domésticos sem tratamento, conforme dados do Censo de 2010. Valores intermediários foram identificados nas estaçôes 4 e 5, com usos mais rurais (chácaras e horta). Tais resultados vão de encontro a estudos semelhantes (KUHLMANN et al., 2014, GASTALDINI, 2014, MENEZES et al., 2016).

Quanto ao oxigênio dissolvido, teores mais elevados foram verificados nas estaçôes com maior predominância de vegetação (estaçôes 1 e 2), e os menores teores na estação 6 , que possui maior uso urbano. Este parâmetro é influenciável por uma série de fatores e, conforme Tundisi (2008), a decomposição de matéria orgânica por atividades microbianas é uma das causas mais importantes de perda de oxigênio dissolvido. Estudos apontam maiores teores de oxigênio dissolvido em córregos com predominância de áreas vegetadas e menores teores em locais com uso urbano, devido a contribuições de esgotos domésticos sem tratamento (KUHLMANN et al., 2014; MENEZES et al., 2016). Nota-se grande diferença de valores de fósforo total entre os usos, apresentando concentraçóes menores nas estaçóes menos antropizadas $(1,2,4,5)$ e maiores teores nas estaçóes com uso e cobertura do solo mais antrópico (3 e 6) devido, principalmente, ao grande aporte de fósforo nos efluentes, pois conforme Von Sperling (2007, p. 478) os esgotos domésticos constituem a maior contribuição de fósforo. Resultados semelhantes foram encontrados por Moruzzi et al.(2012) em bacia hidrográfica na cidade de Itirapina-SP, e por Menezes et al. (2016) na bacia do Ribeirão Vermelho em Lavras, Minas Gerais. Neilen et al. (2017), em estudo em região subtropical da Austrália, concluiu que zonas ripárias arborizadas contribuem mais com a redução do aporte de fósforo para corpos hídricos.

Foi verificada correlação entre pluviosidade e parâmetros de qualidade da água. As pluviosidades acumuladas diárias e mensais constam na Tabela 2.
Tabela 2 - Pluviosidade das 24 horas anteriores à coleta e acumulado mensal ( $\mathrm{mm})$

\begin{tabular}{c|c|c|c}
\hline \multirow{2}{*}{ Período } & $\begin{array}{c}\text { Datas de } \\
\text { coleta }\end{array}$ & $\begin{array}{c}\text { Pluviosidade } \\
24 \mathrm{~h}(\mathrm{~mm})\end{array}$ & $\begin{array}{c}\text { Pluviosidade } \\
\text { mês }(\mathrm{mm})\end{array}$ \\
\hline \multirow{3}{*}{ Seco } & $30 / 04 / 15$ & 14,02 & 93,98 \\
\cline { 2 - 4 } & $30 / 06 / 15$ & 0 & 80,35 \\
\cline { 2 - 4 } & $28 / 08 / 15$ & 11,43 & 31,7 \\
\hline \multirow{2}{*}{ Chuvoso } & $28 / 10 / 15$ & 0,2 & 125,97 \\
\cline { 2 - 4 } & $02 / 03 / 16$ & 29,7 & $270,46^{*}$ \\
\hline
\end{tabular}

Fonte: dados do CEMADEN. *A coleta de março ocorreu no início do mês (02/03), o período de referência para a chuva mensal foi o mês de fevereiro de 2016 até o dia 01/03/2016

As médias, por estação de amostragem, nos períodos seco e chuvoso, dos parâmetros de qualidade da água avaliados podem ser visualizadas na Figura 6. Verificou-se que a temperatura da água apresentou dinâmica distinta entre os períodos seco e chuvoso, apresentando maiores médias no período chuvoso, o que pode estar relacionado a variaçôes de clima (estaçôes do ano).

A Tabela 3 apresenta o resultado do teste de Shapiro-Wilk para os dados do estudo, onde nota-se que nenhum dos parâmetros apresentou distribuição normal $(\mathrm{p}<0,05)$, o que era esperado, visto que, conforme Helsel e Hirsch (2002), dados ambientais, em especial os relacionados à água, em geral apresentam distribuição não normal, a média e a mediana geralmente não coincidem como ocorre na distribuição normal, com assimetria positiva, não apresentam valores negativos.

Tabela 3 - Teste de Shapiro-Wilk

\begin{tabular}{l|c|c}
\hline Parâmetro & Shapiro-Wilk & p-value \\
\hline Turbidez & 0,69891 & 0,00000 \\
\hline $\mathrm{pH}$ & 0,22236 & 0,00000 \\
\hline $\begin{array}{l}\text { Sólidos Totais } \\
\text { Dissolvidos }\end{array}$ & 0,80065 & 0,00007 \\
\hline $\begin{array}{l}\text { Oxigênio } \\
\text { Dissolvido }\end{array}$ & 0,26129 & 0,00000 \\
\hline $\begin{array}{l}\text { Condutividade } \\
\text { Elétrica }\end{array}$ & 0,74834 & 0,00001 \\
\hline $\begin{array}{l}\text { Temperatura } \\
\text { Fósforo Total }\end{array}$ & 0,29983 & 0,00000 \\
\hline
\end{tabular}


Figura 6 - Resultados dos parâmetros de qualidade da água por períodos: seco e chuvoso

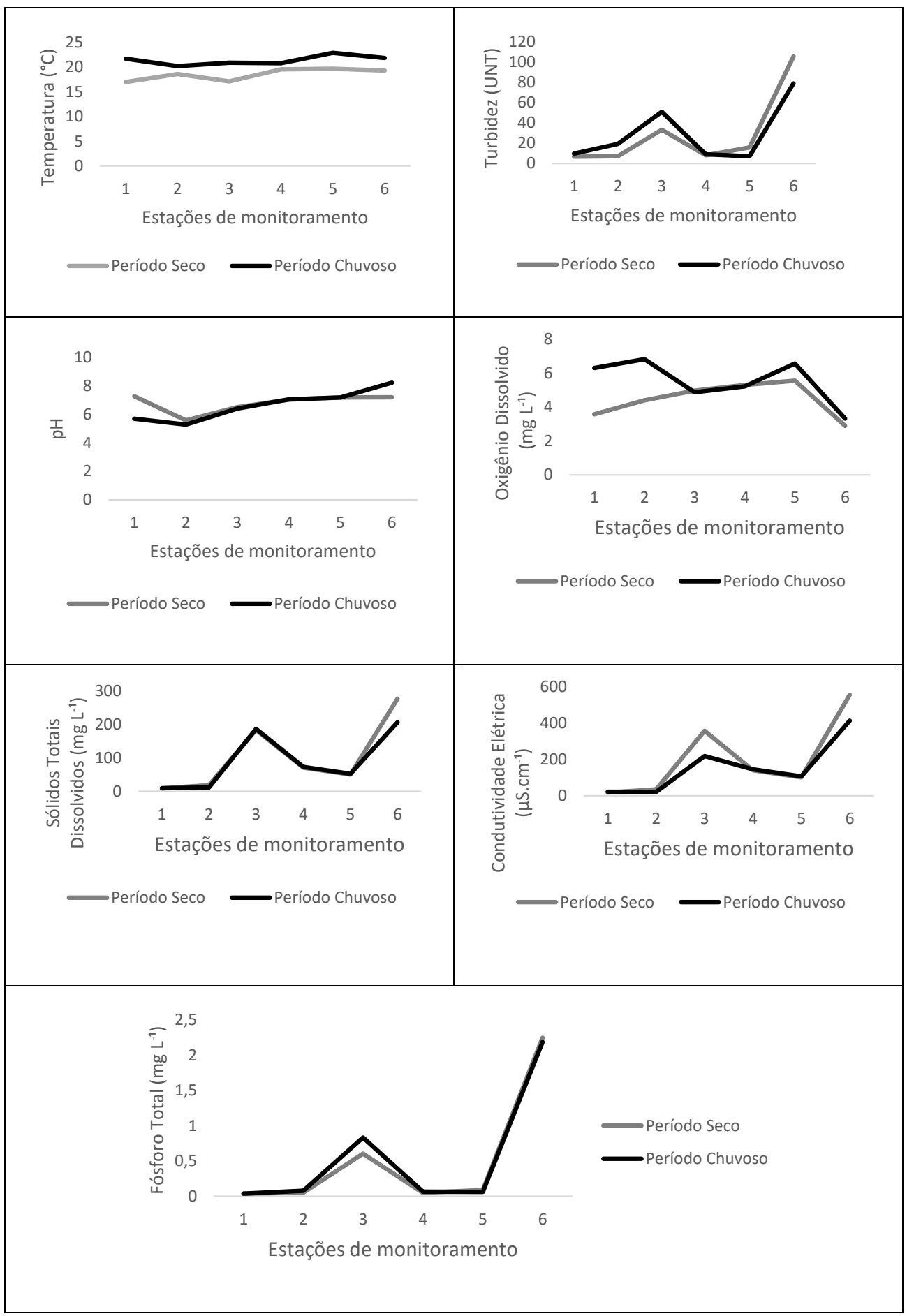


Os resultados da aplicação do teste Kruskal-Wallis encontram-se na Tabela 4.

Tabela 4 - Resultados do teste Kruskal-Wallis para os parâmetros nas diferentes estaçóes de amostragem

\begin{tabular}{l|c}
\hline Parâmetro & Valor de $\mathrm{p}$ \\
\hline Turbidez & $0,02733^{*}$ \\
\hline $\mathrm{pH}$ & $0,00641^{*}$ \\
\hline Sólidos Totais Dissolvidos & $0,00015^{*}$ \\
\hline Oxigênio Dissolvido & $0,26350^{* *}$ \\
\hline Condutividade Elétrica & $0,00039^{*}$ \\
\hline Temperatura & $0,40430^{* *}$ \\
\hline Fósforo Total & $0,01595^{*}$
\end{tabular}

*Há diferença significativa entre as medianas de amostras.

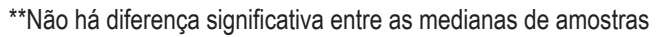

Os parâmetros que apresentaram diferenças significativas entre as médias das amostras, considerados de maior relevância para explicar as diferenças de qualidade da água entre os corpos hídricos analisados, foram: turbidez, $\mathrm{pH}$, sólidos totais dissolvidos, condutividade elétrica e fósforo total. As exceçôes foram os parâmetros: oxigênio dissolvido e temperatura da água.

$\mathrm{O}$ oxigênio dissolvido apresentou médias mais elevadas no período chuvoso para a maioria das estaçóes monitoradas. Souza e Gastaldini (2014) verificaram influência direta dos eventos de precipitação em relação ao oxigênio dissolvido, devido à diluição do volume de água inserido no sistema fluvial em estudo em bacia hidrográfica em Santa Maria, RS. Por sua vez, Zanata et al. (2015) também encontraram correlaçóes fortes para oxigênio dissolvido, temperatura e turbidez, principalmente em meses mais chuvosos como fevereiro e março), ao pesquisar uma bacia em Batatais - SP. Os dados apresentados no presente trabalho evidenciam que a condutividade elétrica e os sólidos totais dissolvidos apresentaram valores mais reduzidos no período chuvoso. Isso pode estar relacionado à diluição de despejos devido às chuvas.

A turbidez mostrou-se mais elevada no período chuvoso nas estaçóes 1, 2 e 3. Isso pode estar relacionado ao aporte de partículas oriundas da lavagem superficial da bacia devido às chuvas.
Menezes et al. (2016), em estudo de bacia em Lavras - MG, encontraram relaçôes entre os padróes do uso do solo e a qualidade da água tanto em períodos chuvosos como secos, predominando contribuiçóes difusas de áreas rurais no período chuvoso, e maiores contribuiçóes de esgotos na deterioração da qualidade da água no período seco.

Os resultados da correlação de Spearman entre a pluviosidade do dia anterior à coleta e os parâmetros de qualidade da água estão na Tabela 5.

Nota-se que houve correlação significativa negativa entre a pluviosidade do dia anterior à coleta e os parâmetros turbidez, sólidos totais dissolvidos (STD) e fósforo total (PT) na estação 5, caracterizada por horticultura, ou seja, aumento da concentração em menor pluviosidade. Santos e Hernandez (2013) observaram moderada elevação na concentração de sólidos nos períodos de estiagem em áreas rurais caracterizadas pela ausência de manejo adequado do solo, bem como em áreas com alta densidade de estradas, o que pode auxiliar no entendimento desse comportamento na microbacia com horticultura, pois pode estar sob manejo inadequado do solo.

$\mathrm{Na}$ estação 1, com predominância de mata, o fósforo total foi significativo segundo a correlaçáo de Spearman, com correlação negativa, o que pode estar associado à reaçáo deste elemento com materiais orgânicos de origem natural ou antrópica, como caso da microbacia 5.

Houve resultado significante para a correlação entre a pluviosidade e o oxigênio dissolvido na estação 6 , sendo uma correlaçáo positiva, ou seja, aumento do teor de OD com uma maior intensidade da pluviosidade. Neste caso, o resultado pode ser explicado pela maior diluição dos esgotos domésticos que o córrego recebe, resultado semelhante foi identificado por Menezes et al. (2016) que verificaram melhoria da qualidade da água em período úmido em córregos com contribuiçóes de esgotos.

Os resultados da correlação de Spearman para a pluviosidade acumulada mensal constam na Tabela 6 . É possível verificar que houve correlação significativa entre a temperatura da água nas estações 1, 3 e 5, sendo uma correlação positiva, com aumento da temperatura tendo em vista maior pluviosidade. Isso pode ser explicado pelos fatores climáticos, visto que nessa região as maiores temperaturas coincidem com 
Tabela 5 - Correlação de Spearman para pluviosidade 24 horas e os parâmetros de qualidade da água

\begin{tabular}{|c|c|c|c|c|c|c|}
\hline \multirow{2}{*}{ Parâmetro/ pluviosidade $24 \mathrm{~h}$} & \multicolumn{6}{|c|}{ Estaçôes de amostragem } \\
\hline & 1 & 2 & 3 & 4 & 5 & 6 \\
\hline \multicolumn{7}{|l|}{ Temperatura da água } \\
\hline Correlação de Spearman & 0,700 & 0,500 & 0,700 & 0,800 & 0,700 & 0,832 \\
\hline $\mathrm{p}$-value & 0,188 & 0,391 & 0,188 & 0,104 & 0,188 & 0,168 \\
\hline Significância* & NS & NS & NS & NS & NS & NS \\
\hline \multicolumn{7}{|l|}{ Turbidez } \\
\hline Correlação de Spearman & $-0,100$ & $-0,500$ & $-0,100$ & 0,200 & $-0,900$ & $-0,832$ \\
\hline $\mathrm{p}$-value & 0,873 & 0,391 & 0,873 & 0,747 & 0,037 & 0,168 \\
\hline Significância* & NS & NS & NS & NS & $S$ & NS \\
\hline \multicolumn{7}{|l|}{$\mathrm{pH}$} \\
\hline Correlação de Spearman & $-0,600$ & $-0,200$ & $-0,100$ & 0,100 & $-0,364$ & $-0,529$ \\
\hline $\mathrm{p}$-value & 0,285 & 0,747 & 0,873 & 0,873 & 0,547 & 0,471 \\
\hline Significância* & NS & NS & NS & NS & NS & NS \\
\hline \multicolumn{7}{|l|}{ Oxigênio Dissolvido } \\
\hline Correlação de Spearman & 0,700 & 0,400 & 0,100 & $-0,100$ & $-0,100$ & 0,983 \\
\hline p-value & 0,188 & 0,505 & 0,873 & 0,873 & 0,873 & 0,017 \\
\hline Significância* & NS & NS & NS & NS & NS & S \\
\hline \multicolumn{7}{|l|}{ Sólidos Totais Dissolvidos } \\
\hline Correlação de Spearman & 0,756 & 0,300 & $-0,100$ & $-0,500$ & $-0,674$ & $-0,378$ \\
\hline p-value & 0,139 & 0,624 & 0,873 & 0,391 & 0,009 & 0,622 \\
\hline Significância* & NS & NS & NS & NS & $S$ & NS \\
\hline \multicolumn{7}{|l|}{ Condutividade Elétrica } \\
\hline Correlação de Spearman & 0,606 & 0,300 & $-0,600$ & $-0,500$ & $-0,600$ & $-0,832$ \\
\hline $\mathrm{p}$-value & 0,278 & 0,624 & 0,285 & 0,391 & 0,285 & 0,168 \\
\hline Significância* & NS & NS & NS & NS & NS & NS \\
\hline \multicolumn{7}{|l|}{ Fósforo Total } \\
\hline Correlação de Spearman & $-0,900$ & $-0,800$ & $-0,100$ & $-0,800$ & $-0,900$ & $-0,832$ \\
\hline $\mathrm{p}$-value & 0,037 & 0,104 & 0,873 & 0,104 & 0,037 & 0,168 \\
\hline Significância* & $S$ & NS & NS & NS & $S$ & NS \\
\hline
\end{tabular}

*Valor de $p \leq \alpha$ ( $\alpha$ ou alfa de 0,05$)$ : a correlação é estatisticamente significativa (S), do contrário é não significativa (NS) 
Tabela 6 - Correlação de Spearman para pluviosidade 30 dias e os parâmetros de qualidade da água

\begin{tabular}{|c|c|c|c|c|c|c|}
\hline \multirow{2}{*}{ Parâmetro/ pluviosidade $30 \mathrm{~d}$} & \multicolumn{6}{|c|}{ Estações amostrais } \\
\hline & 1 & 2 & 3 & 4 & 5 & 6 \\
\hline \multicolumn{7}{|l|}{ Temperatura da água } \\
\hline Correlação de Spearman & 0,900 & 0,500 & 0,900 & 0,600 & 0,900 & 0,849 \\
\hline p-value & 0,037 & 0,391 & 0,037 & 0,285 & 0,037 & 0,151 \\
\hline Significância* & $S$ & NS & $S$ & NS & $S$ & NS \\
\hline \multicolumn{7}{|l|}{ Turbidez } \\
\hline Correlação de Spearman & $-0,200$ & 0,000 & $-0,200$ & $-0,100$ & $-0,800$ & $-0,141$ \\
\hline p-value & 0,747 & 1,000 & 0,747 & 0,873 & 0,104 & 0,859 \\
\hline Significância* & NS & NS & NS & NS & NS & NS \\
\hline \multicolumn{7}{|l|}{$\mathrm{pH}$} \\
\hline Correlação de Spearman & $-0,700$ & 0,100 & 0,300 & 0,200 & 0,243 & $-0,283$ \\
\hline p-value & 0,188 & 0,873 & 0,624 & 0,747 & 0,694 & 0,717 \\
\hline Significância* & NS & NS & NS & NS & NS & NS \\
\hline \multicolumn{7}{|l|}{ Oxigênio Dissolvido } \\
\hline Correlação de Spearman & 0,400 & 0,300 & $-0,300$ & $-0,200$ & $-0,200$ & 0,424 \\
\hline p-value & 0,505 & 0,624 & 0,624 & 0,747 & 0,747 & 0,576 \\
\hline Significância* & NS & NS & NS & NS & NS & NS \\
\hline \multicolumn{7}{|l|}{ Sólidos Totais Dissolvidos } \\
\hline Correlação de Spearman & 0,189 & 0,100 & $-0,200$ & $-0,500$ & $-0,577$ & $-0,707$ \\
\hline p-value & 0,761 & 0,873 & 0,747 & 0,391 & 0,308 & 0,293 \\
\hline Significância* & NS & NS & NS & NS & NS & NS \\
\hline \multicolumn{7}{|l|}{ Condutividade Elétrica } \\
\hline Correlação de Spearman & 0,364 & 0,100 & $-0,700$ & $-0,500$ & $-0,700$ & $-0,849$ \\
\hline p-value & 0,547 & 0,873 & 0,188 & 0,391 & 0,188 & 0,151 \\
\hline Significância* & NS & NS & NS & NS & NS & NS \\
\hline \multicolumn{7}{|l|}{ Fósforo Total } \\
\hline Correlação de Spearman & $-0,300$ & $-0,100$ & $-0,200$ & $-0,100$ & $-0,500$ & $-0,141$ \\
\hline $\mathrm{p}$-value & 0,624 & 0,873 & 0,747 & 0,873 & 0,391 & 0,859 \\
\hline Significância* & NS & NS & NS & NS & NS & NS \\
\hline
\end{tabular}

*Valor de $p \leq a$ (a ou alfa de 0,05): a correlação é estatisticamente significativa (S), do contrário é não significativa (NS)

o período de verão que apresenta maiores pluviosidades (CEPAGRI; UNICAMP, s.d.). No entanto, uma amostragem por períodos mais longos poderia auxiliar a confirmar essa hipótese, bem como explicar porque não se verificou semelhança nas demais estações.

Os resultados da análise da correlação da qualidade da água com o uso e a ocupação do solo estão na
Tabela 7, que apresenta o coeficiente de correlação de Spearman entre a média dos parâmetros por estação e a porcentagem de mata na respectiva microbacia, bem como a significância dos resultados. Nenhum parâmetro apresentou correlação significativa com a porcentagem de Mata. No entanto, para alguns parâmetros houve correlaçóes relativamente fortes 
Tabela 7 - Correlação de Spearman entre os parâmetros e \% mata por estação

\begin{tabular}{|c|c|c|c|c|c|c|c|c|}
\hline \multirow{2}{*}{$\begin{array}{c}\text { Microbacia/ } \\
\text { Estação }\end{array}$} & \multirow{2}{*}{$\%$ Mata } & \multicolumn{7}{|c|}{ Médias } \\
\hline & & Temp. & Turbidez & $\mathrm{pH}$ & OD & STD & CE & PT \\
\hline 1 & 99,19 & 18,88 & 7,93 & 6,63 & 4,66 & 9 & 19,4 & 0,04 \\
\hline 2 & 74,74 & 19,26 & 11,96 & 5,46 & 5,36 & 15,6 & 29,8 & 0,06 \\
\hline 3 & 76,30 & 18,65 & 40,4 & 6,47 & 4,92 & 185 & 301,6 & 0,69 \\
\hline 4 & 56,74 & 20,09 & 8,43 & 7,04 & 5,27 & 71,6 & 142,4 & 0,06 \\
\hline 5 & 70,61 & 20,98 & 12,42 & 7,19 & 5,96 & 51,2 & 103,2 & 0,08 \\
\hline 6 & 26,98 & 20,59 & 92,25 & 7,71 & 3,11 & 241,75 & 483,5 & 2,22 \\
\hline \multicolumn{2}{|c|}{ Correlação de Spearman } & $-0,714$ & $-0,771$ & 0,029 & $-0,486$ & $-0,657$ & $-0,657$ & $-0,486$ \\
\hline \multicolumn{2}{|c|}{$\mathrm{p}$-value } & 0,111 & 0,072 & 0,957 & 0,329 & 0,156 & 0,156 & 0,329 \\
\hline \multicolumn{2}{|c|}{ Significância* } & NS & NS & NS & NS & NS & NS & NS \\
\hline
\end{tabular}

${ }^{*}$ Valor de $p \leq a$ (a ou alfa de 0,05 ): a correlação é estatisticamente significativa (S), do contrário é não significativa (NS)

Temp.=Temperatura; $\mathrm{OD}=0$ xigênio Dissolvido; $\mathrm{STD}=$ Sólidos Totais Dissolvidos; $\mathrm{CE}=$ Condutividade Elétrica; $\mathrm{PT}=$ Fósforo Total

em relação aos demais (coeficiente Spearman mais próximos de 1 ou -1$)$ como turbidez (-0,771), STD e CE $(-0,657)$. Trata-se de correlaçóes negativas, ou seja, a maior porcentagem de mata pode estar relacionada a menores valores para esses parâmetros, evidenciando o papel da mata na reduçáo do aporte de partículas sedimentares nos cursos d'água.

Em relação aos usos considerados moderadamente antropizados, isto é, usos rurais (chácaras e horticul- tura), os resultados constam na Tabela 8. A correlação dos parâmetros náo foi significativa, isto é, usos rurais não foram determinantes para provocar alteraçôes na qualidade da água. Ressalta-se que tais classes de uso não apresentaram porcentagem elevada nas microbacias, estando mais presentes na microbacia estação $4(37,11 \%)$ e microbacia da estação $5(18,08 \%)$.

A Tabela 9 apresenta a correlação entre a média dos parâmetros por estaçáo e a porcentagem de usos mais

Tabela 8 - Correlação de Spearman entre os parâmetros e \% usos moderadamente antropizados por estação

\begin{tabular}{|c|c|c|c|c|c|c|c|c|}
\hline \multirow{2}{*}{$\begin{array}{c}\text { Microbacia / } \\
\text { Estação }\end{array}$} & \multirow{2}{*}{$\begin{array}{c}\text { \% Uso } \\
\text { Antrópico } \\
\text { Moderado }\end{array}$} & \multicolumn{7}{|c|}{ Média } \\
\hline & & Temp. & Turbidez & $\mathrm{pH}$ & OD & STD & CE & PT \\
\hline 1 & 0,00 & 18,88 & 7,93 & 6,63 & 4,66 & 9 & 19,4 & 0,04 \\
\hline 2 & 3,38 & 19,26 & 11,96 & 5,46 & 5,36 & 15,6 & 29,8 & 0,06 \\
\hline 3 & 6,04 & 18,65 & 40,4 & 6,47 & 4,92 & 185 & 301,6 & 0,69 \\
\hline 4 & 37,11 & 20,09 & 8,43 & 7,04 & 5,27 & 71,6 & 142,4 & 0,06 \\
\hline 5 & 18,08 & 20,98 & 12,42 & 7,19 & 5,96 & 51,2 & 103,2 & 0,08 \\
\hline 6 & 0,00 & 20,59 & 92,25 & 7,71 & 3,11 & 241,75 & 483,5 & 2,22 \\
\hline \multicolumn{2}{|c|}{ Correlaçáo de Spearman } & 0,641 & 0,428 & 0 & $-0,214$ & 0,214 & 0,214 & $-0,214$ \\
\hline \multicolumn{2}{|c|}{$\mathrm{p}$-value } & 0,170 & 0,398 & 1 & 0,684 & 0,684 & 0,684 & 0,684 \\
\hline \multicolumn{2}{|c|}{ Significância* } & NS & NS & NS & NS & NS & NS & NS \\
\hline
\end{tabular}

*Valor de $p \leq a$ (a ou alfa de 0,05): a correlação é estatisticamente significativa (S), do contrário é não significativa (NS)

Temp.=Temperatura; OD=Oxigênio Dissolvido; STD=Sólidos Totais Dissolvidos; CE=Condutividade Elétrica; PT=Fósforo Total. 
Tabela 9 - Correlação de Spearman entre os parâmetros e \% usos mais antropizados por estação

\begin{tabular}{|c|c|c|c|c|c|c|c|c|}
\hline \multirow{2}{*}{$\begin{array}{l}\text { Microbacia } \\
\text { / Estaçáo }\end{array}$} & \multirow{2}{*}{$\begin{array}{c}\text { \% Usos mais } \\
\text { Antropizados } \\
\text { (urb.,favela) }\end{array}$} & \multicolumn{7}{|c|}{ Médias } \\
\hline & & Temp. & Turbidez & $\mathrm{pH}$ & OD & STD & $\mathrm{CE}$ & PT \\
\hline 1 & 0,00 & 18,88 & 7,93 & 6,63 & 4,66 & 9 & 19,4 & 0,04 \\
\hline 2 & 0,00 & 19,26 & 11,96 & 5,46 & 5,36 & 15,6 & 29,8 & 0,06 \\
\hline 3 & 11,84 & 18,65 & 40,4 & 6,47 & 4,92 & 185 & 301,6 & 0,69 \\
\hline 4 & 0,00 & 20,09 & 8,43 & 7,04 & 5,27 & 71,6 & 142,4 & 0,06 \\
\hline 5 & 0,00 & 20,98 & 12,42 & 7,19 & 5,96 & 51,2 & 103,2 & 0,08 \\
\hline 6 & 61,26 & 20,59 & 92,25 & 7,71 & 3,11 & 241,75 & 483,5 & 2,22 \\
\hline \multicolumn{2}{|c|}{ Correlação de Spearman } & 0,064 & 0,831 & 0,447 & $-0,703$ & 0,831 & 0,831 & 0,831 \\
\hline \multicolumn{2}{|l|}{ p-value } & 0,904 & 0,041 & 0,374 & 0,119 & 0,041 & 0,041 & 0,041 \\
\hline \multicolumn{2}{|l|}{ Significância* } & NS & $S$ & NS & NS & $S$ & $S$ & $S$ \\
\hline
\end{tabular}

*Valor de $p \leq a$ (a ou alfa de 0,05): a correlação é estatisticamente significativa (S), do contrário é não significativa (NS) Temp.=Temperatura;

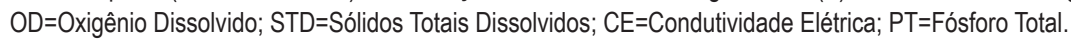

antropizados (área urbanizada e favela), nas respectivas microbacias. Os resultados mostram que a correlação foi significativa e positiva entre a porcentagem de usos mais antropizados e os parâmetros Turbidez, Sólidos Totais Dissolvidos, Condutividade Elétrica e Fósforo Total. Tais resultados corroboram a influência do uso urbano, principalmente sem tratamento dos efluentes despejados nos corpos hídricos, conforme os dados do IBGE, aumentando o aporte de partículas e nutrientes, reduzindo oxigênio dissolvido na água, o que leva à degradação da qualidade da água.

Turbidez, sólidos totais dissolvidos, condutividade elétrica e fósforo total apresentaram maiores valores nas estaçôes cujas microbacias possuem predominância de usos antrópicos (uso urbano, favela, chácaras, hortas) quando comparados aos usos naturais (mata). Tais parâmetros podem estar relacionados à ocorrência de erosão e deposição de partículas, bem como despejos de efluentes.

Vrebos et al. (2017) encontraram influências do uso do solo rural e urbano sobre a qualidade de parâmetros físico-químicos da água em sub-bacia na Bélgica, tanto no inverno quanto no verão, notadamente para os parâmetros oxigênio dissolvido e fósforo total.

Souza e Gastaldini (2014) obtiveram menores valores de condutividade elétrica em bacia hidrográfica de área mais preservada; e valores mais elevados de condutividade elétrica, sólidos totais dissolvidos e turbidez em áreas menos vegetadas, com maior potencial de erosão. Baixas concentraçôes de oxigênio dissolvido foram observadas, no mesmo estudo, nas bacias hidrográficas com maior número de habitantes, relacionadas a despejos de efluentes domésticos, com contribuição elevada de matéria orgânica aos sistemas fluviais. Concentraçóes mais elevadas de fósforo total em áreas urbanizadas também foram verificadas por Menezes et al. (2016).

Os resultados quanto ao atendimento à legislação podem ser observados na Figura 7. A maioria das estaçóes apresentou turbidez abaixo do limite máximo permitido, exceto a estaçáo 6 , que ultrapassou em duas datas distintas o limite máximo permitido pela Resolução para corpo hídrico enquadrado em classe 2 .

A maior parte dos locais apresentou o $\mathrm{pH}$ dentro da faixa exigida pela Resolução CONAMA $n^{\circ} 357 / 2005$ para corpos hídricos de classe 2. As estaçôes 1 e 2 apresentaram valores de $\mathrm{pH}$ abaixo do requerido na Resolução CONAMA no 357/05. Tal ocorrência pode ser explicada pelo fato de ambas as estaçôes possuírem vegetação natural nas margens dos córregos e liberação de ácidos húmicos. A estação 6, por sua vez, apresentou valor mais elevado do que o permitido em outubro, o que pode estar relacionado ao despejo de efluentes que esse córrego recebe. 
Figura 7- Comparaçáo dos resultados dos parâmetros de qualidade de água com os padróes estabelecidos pela Resolução CONAMA 357/2005 nas seis estaçóes de amostragem

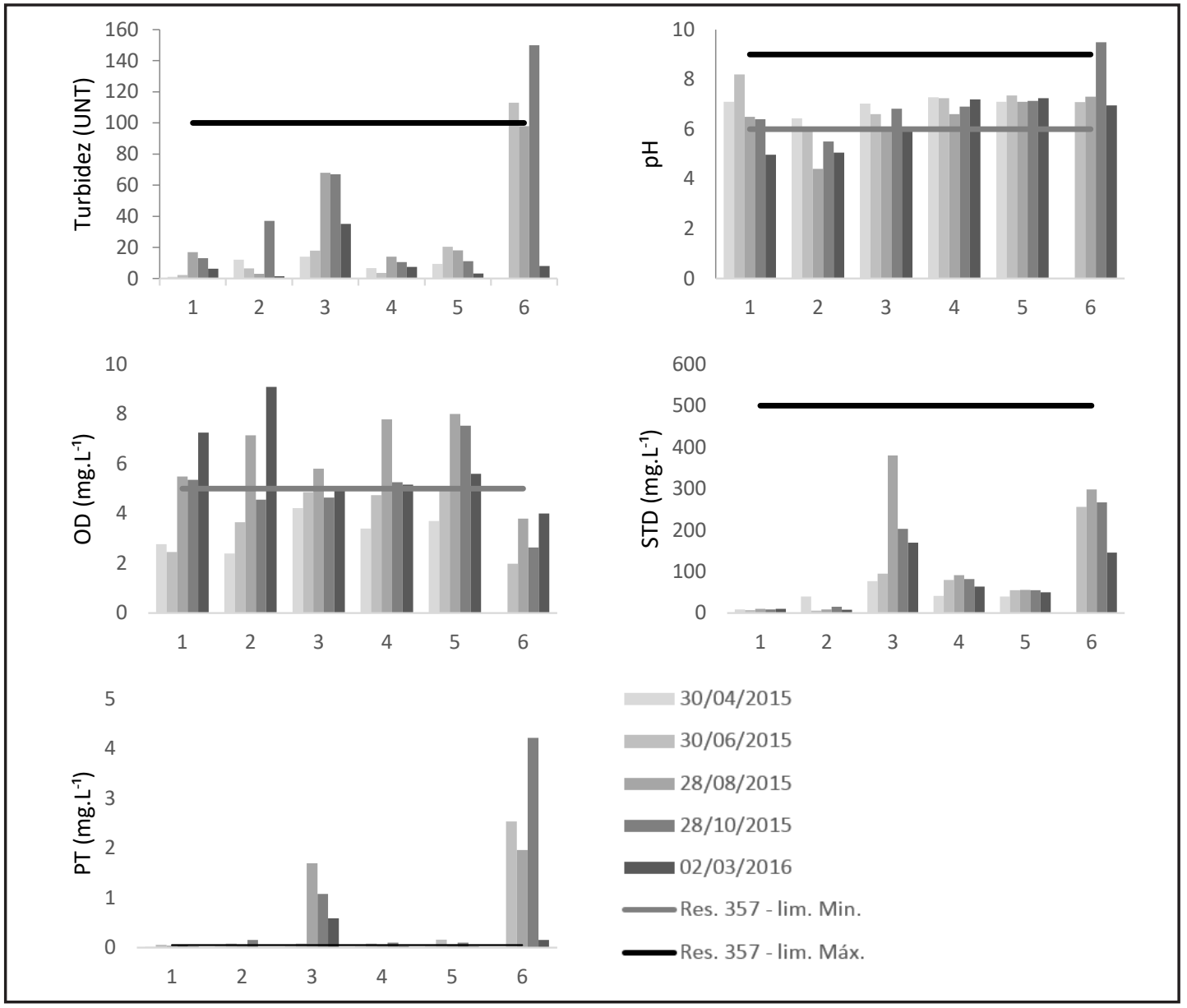

Todas as estaçóes, em algum momento, desatenderam os requisitos de oxigênio dissolvido, principalmente as estaçóes 3 e 6 , evidenciando a influência dos esgotos recebidos pelos córregos. Para as demais estaçôes, seria preciso verificar os motivos, em especial, sendo o oxigênio dissolvido um parâmetro influenciável por uma série de fatores, como temperatura, e relação entre o meio ar-água no qual a vazão pode exercer influência. Destaca-se que a referida norma determina os padrôes segundo a vazão de referência, a qual não é especificada, deixando em aberto um relevante critério de enquadramento, pois a vazão varia e influencia a concentração dos parâmetros (TUCCI, 2009).
Em relação aos sólidos totais dissolvidos, todos os locais apresentaram valores dentro do permitido pela Resolução CONAMA.

As estaçóes 3 e 6 ultrapassam o limite de fósforo total em todos os períodos coletados, indicando o grande aporte de fósforo para a represa Billings por contribuição de córregos com lançamento de esgotos sem tratamento.

\section{CONCLUSÓES}

O estudo demonstrou que o uso e cobertura do solo nas microbacias exerce influência nos parâmetros da qualidade da água analisados. Ressalvadas as limi- 
taçóes do trabalho, principalmente quanto ao curto período de análise, os procedimentos adotados possuem aplicabilidade para outros estudos semelhantes em outras áreas, podendo ser adotados em qualquer escala espacial. No entanto, com maior confiabilidade se aplicado a escalas menores. Em suma, o estudo demonstrou a importância da preservação de áreas vegetadas em áreas de mananciais a fim de contribuir com a qualidade das águas.

A pluviosidade das 24 horas anteriores à coleta e a pluviosidade mensal apresentaram correlaçóes pouco significativas com os parâmetros de qualidade da água, sendo estas mais presentes na estação 5 , possivelmente pela lixiviação de partículas oriundas da área de horticultura presente na microbacia. Apesar de presente em apenas uma das microbacias, o uso agrícola representado pela horticultura apresentou influência moderada sobre os parâmetros turbidez, sólidos totais dissolvidos e fósforo total, apresentando maiores teores após chuvas no dia anterior, apontando para a necessidade do correto manejo do solo nessas áreas, a fim de evitar processos de erosão e assoreamento.

Os parâmetros de qualidade da água utilizados neste estudo mostraram-se suficientes para demonstrar sua relação com o uso do solo nas microbacias, em especial os parâmetros: turbidez, $\mathrm{pH}$, sólidos totais dissolvidos, condutividade elétrica e fósforo total, com diferenças significativas entre as microbacias, verificadas por meio do teste Kruskal-Wallis. Verificou-se que as microbacias com maiores porcentagens de uso do solo do tipo Mata apresentaram melhor qualidade da água, para turbidez, condutividade elétrica e fósforo total. Os usos mais antropizados apresentaram queda da qualidade da água para os parâmetros: Turbidez, Sólidos Totais Dissolvidos, Condutividade Elétrica e Fósforo Total com relaçóes estatisticamente significativas conforme correlação de
Spearman. O agrupamento das classes de uso do solo proposto conforme o grau de antropização permitiu uma abordagem geral e quantitativa, contribuindo como método para estimar correlação do uso do solo e a qualidade da água a partir da análise de parâmetros físicos e químicos.

Os resultados demonstraram que houve desatendimentos à Resolução CONAMA no357/2005, portanto recomenda-se o monitoramento para averiguação do atendimento aos padrôes dos corpos hídricos à respectiva classe de enquadramento. No entanto, alguns parâmetros apresentaram sazonalidades, o que permite questionar o fato desta norma não considerar que podem ocorrer alteraçóes naturais que podem alterar os parâmetros de qualidade da água. Por exemplo, ao afirmar que nenhuma amostra deve ter padrão de oxigênio dissolvido inferior ao limite, deve ser questionado se um fator influenciável por temperatura, por exemplo, não deveria ter uma quantidade mínima de amostras para avaliação.

As diversas formas de uso e ocupação do solo exercem influências sobre a qualidade da água. Nesse sentido, a gestão por microbacias é recomendada para adoção de instrumentos de controle e planejamento do uso do solo visando à proteção dos recursos hídricos, principalmente por áreas vegetadas. Instrumentos como Plano Diretor e Plano de Bacia Hidrográfica devem ser utilizados de forma integrada com esse fim.

Recomenda-se o avanço da coleta e do tratamento de esgotos na região, além do monitoramento da qualidade da água para acompanhamento do atendimento aos padróes requeridos, visando também à proteção do manancial de abastecimento.

Recomenda-se que estudos futuros acompanhem alteraçóes no uso e ocupação do solo, bem como da coleta de esgotos, para verificar se houve mudança na qualidade da água.

\section{Referências}

BRASIL, Lei $n^{\circ}$ 9.433, de 8 de janeiro de 1997. Institui a Política Nacional de Recursos Hídricos. Diário Oficial da União, Brasília, DF, 9 de janeiro de 1999.

BRASIL. Ministério do Meio Ambiente. Conselho Nacional do Meio Ambiente, CONAMA. Resolução n 357, de 17 de março de 2005. Dispõe sobre a classificação dos corpos de água e diretrizes ambientais para o seu enquadramento, bem como estabelece as condições e padrões de lançamento de efluentes, e dá outras providências. Diário Oficial da União, Brasília, DF, 18 de março de 2005, págs. 58-63. Disponível em http://www.mma.gov.br/port/CONAMA/res/res05/res35705.pdf. Acesso em: 18.abr.2015. 
CENTRO DE PESQUISAS METEOROLOGICAS E CLIMÁTICAS APLICADAS AAGRICULTURA-CEPAGRI; UNIVERSIDADE ESTADUAL DE CAMPINAS - UNICAMP. Clima dos Municípios Paulistas: A classificação climática de Koeppen para o estado de São Paulo. S.d. Disponível em http://www.cpa.unicamp.br/outras-informacoes/clima-dos-municipiospaulistas.html. Acesso em: 08 jul.2015.

CENTRO NACIONAL DE MONITORAMENTO E ALERTAS DE DESASTRES NATURAIS - CEMADEN. Dados pluviométricos por estação automática. sd. Disponível em http://www.cemaden.gov.br/mapainterativol. Acesso em: 15 abr.2016.

COELHO, R. C. T. P.; BUFFON, I.; GUERRA, T. Influência do uso e ocupação do solo na qualidade da água: um método para avaliar a importância da zona ripária. Ambi-Agua, Taubaté, v. 6, n. 1, p. 104-117, 2011.

COMPANHIAAMBIENTAL DO ESTADO DE SÃO PAULO - CETESB; AGÊNCIA NACIONAL DE ÁGUAS - ANA. Guia nacional de coleta e preservação de amostras: água, sedimento, comunidades aquáticas e efluentes líquidos. Carlos J.B. et al. (Org.). São Paulo: CETESB; Brasilia: ANA, 2011, 326 p.: il.

EMPRESA BRASILEIRA DE PESQUISA AGROPECUÁRIA - EMBRAPA; ESCOLA SUPERIOR DE AGRICULTURA "LUIZ DE QUEIROZ" ESALQ/USP. Banco de dados climáticos do Brasil, 2003. Disponivel em: http://www.bdclima.cnpm.embrapa.br/resultados/balanco. php?UF=\&COD=462. Acesso em: 18 jan. 2016.

EMPRESA PAULISTA DE PLANEJAMENTO METROPOLITANO S.A. - EMPLASA Atlas de Uso e Ocupação do Solo da RMSP. São Paulo, SP, 2003.

EMPRESA PAULISTA DE PLANEJAMENTO METROPOLITANO S.A. - EMPLASA. Cartas planialtimétricas da RMSP na escala 1:10.000, 1980/1981.

FERNANDES, M.M; CEDDIA, M.B.; RAMOS, G. M.; GASPAR, A.; MOURA, M.R. Influência do uso do solo na qualidade de água da microbacia Glória, Macaé - RJ. Engenharia Ambiental - Espírito Santo do Pinhal, v. 8, n. 2, abr. Jjun. 2011, p. 105-116.

FUNDAÇÃO NACIONAL DE SAÚDE - FUNASA. Manual de controle da qualidade da água para técnicos que trabalham em ETAS. Ministério da Saúde, Fundação Nacional de Saúde. Brasília: Funasa, 2014, 112 p.

GINEVAN, M. E. Statistical tools for environmental quality measurement. USA: CRC Press, 2004, 239 p.

HAMER, Ø. 2018. PAST PAleontological STatistics Version 3.19. Reference manual. Natural History Museum University of Oslo. 259 p.

HELSEL, D.R.; HIRSCH, R.M. Statistical Methods in Water Resources in Techniques of Water-Resources Investigation. Book 4, chapter A3. U.S.:Geological Survey, 2002.

HORTON, R.E. Erosional development of streams and their drainage basins: hidrophysical approach to quantitative morphology. Bulletin of the Geological Society of America, v.56, n.3, p.275-370, 1945. Disponível em http://www.geos.ed.ac.uk/homes/s0451705/horton_1945. pdf. Acesso em: 01 mar.2016

INSTITUTO BRASILEIRO DE GEOGRAFIA E ESTATÍSTICA - IBGE. Censo demográfico 2010. Brasília: Diário Oficial da União, n. 211, Seção 1, p. 110.

INSTITUTO SOCIOAMBIENTAL - ISA. Billings 2000: ameaças e perspectivas para o maior reservatório de água da região metropolitana de São Paulo: relatório do diagnóstico socioambiental participativo da bacia hidrográfica da Billings no período 1989-99. CAPOBIANCO, J.P.R.; WHATELY, M. org. São Paulo: Instituto Socioambiental, 2002, 60 p. 
KUHLMANN, M.L.; IMBIMBO, H.R.V.; OGURA, L.L.; VILLANI, J.P.; STARZYNSKI, R.; DE JESUS ROBIM, M. Effects of human activities on rivers located in protected areas of the Atlantic Forest. Acta Limnologica Brasiliensia. Volume 26, Issue 1, 2014, Pages 60-72.

LAPPONI, J.C. Estatística usando Excel. Rio de Janeiro: Elsevier, 2005, 476p.

LIMA, W.P.; ZAKIA, M.J.B. Indicadores hidrológicos em áreas florestais. Série técnica IPEF, v.12, n. 31, p. 53-64, abr. 1998.

MENEZES, J.P.C.; BITTENCOURT, R.P.; FARIAS, M.S.; BELLO, I.P.; FIA, R.; OLIVEIRA, L.F.C. Relação entre padrões de uso e ocupação do solo e qualidade da água em uma bacia hidrográfica urbana. Engenharia Sanitária e Ambiental, v.21, n.3, jul/set 2016, p. 519-534.

MORUZZI, R.B.; CONCEIÇÃO, F. T.; SARDINHA, D. S.; HONDA, F. P.; NAVARRO, G. R.B. Avaliação de cargas difusas e simulação de autodepuração no córrego da Água Branca, Itirapina (SP). Geociências, São Paulo, v.31 n.3, p.447- 458, 2012.

NEILEN, A.D.; CHEN, C.R.; PARKER, B.M.; FAGGOTTER, S. J.; BURFORD, M .A. Differences in nitrate and phosphorus export between wooded and grassed riparian zones from farmland to receiving waterways under varying rainfall conditions. Science of the Total Environment, №598 (2017), pg. 188-197.

OMETO, J.P.H.B.; MARTINELLI, L.A.; BALLESTER, M.A.; GESSNER A; JRUSCHE, A.V.; VICTORIA, R.L.; WILLIAMS, M. Effects of land use on water chemistry and macroinvertebrates in two streams of Piracicaba river basin, south-east Brazil. Freshwater Biology, v.44, n.2, p. 327337, jun. 2000.

SANTOS, G.O.; HERNANDEZ, F.BT. Uso do solo e monitoramento dos recursos hídricos no córrego do Ipê, llha Solteira, SP. Revista. Brasileira de Engenharia Agrícola e Ambiental, v.17, n.1, p.60-68, 2013.

SÃO PAULO (Estado). Decreto no 10.755, de 22 de novembro de 1977. Dispõe sobre o enquadramento dos corpos de água receptores na classificação prevista no Decreto n 8.468 , de 8 de setembro de 1976, e dá providências correlatas. Disponível em http://licenciamento. cetesb.sp.gov.br/legislacao/estadual/decretos/1997_Dec_Est_10755.pdf. Acesso em: 18.abr.2015.

SILVA, E.F.L.P.; PIRES, J. S. R.; HARDT, E.; SANTOS, J.E.; FERREIRA, W.A. Avaliação da qualidade da água em microbacias hidrográficas de uma Unidade de Conservação do Nordeste do estado de São Paulo, Brasil. Revista Brasileira de Biociências, Porto Alegre, v. 9, n. 3, p. 371-381, jul./set. 2011.

SISTEMA NACIONAL DE INFORMAÇÕES SOBRE SANEAMENTO - SNIS. Tabelas Completas de informações e indicadores dos prestadores de serviços de saneamento, dados de 2014. Disponivel em: http://www.snis.gov.brl. Acesso em: 31 ago.2016.

SOUZA, M. M.; GASTALDINI, M. C. C. Avaliação da qualidade da água em bacias hidrográficas com diferentes impactos antrópicos. Engenharia Sanitária e Ambiental, v.19, n.3, jul./set. 2014.

STRICKLAND, J.D.H.; PARSONS, T.R. A manual of sea water analysis. Fisheries Research Board of Canadá, Ottawa, n.125, 1960.

TUCCI, C. E. M. Vazão de referência. RHAMA. 2009. (site) <http://rhama.com.br/blog/index.php/sem-categoria/vazao-de-referencia/>.Acesso 13 mar.2018

VALDERRAMA, G.C. The simultaneous analysis of total nitrogen and total phosphorus in natural waters. Marine Chemistry, v.10, p.109-112, 1981.

VON SPERLING, M. Introdução à qualidade das águas e ao tratamento de esgotos. 3 ed. Belo Horizonte: Departamento de Engenharia Sanitária e Ambiental; Universidade Federal de Minas Gerais; 2005. 452p. 
VREBOS, D. BEAUCHARD, O., MEIRE, P. The impact of land use and spatial mediated processes on the water quality in a river system. Science of the Total Environment, nºs 601-602 (2017), pg. 365-373.

ZAMPELLA, R.A.; PROCOPIO, N.A.; LATHROP, R.G.; DOW, C.L. Relationship of land-use/land-cover patterns and surface-water quality in the Mullica River basin. Journal of the American Water Resources Association, v. 43, n. 3, p. 594-604, jun. 2007.

Paula Lopes de Araujo Universidade Federal do ABC

Programa de Pós-Graduação em Ciência Tecnologia Ambiental, SP, Brasil e-mail: plaraujox@gmail.com

Contribuição do autor:

Pesquisa realizada como parte de estudo de projeto de mestrado do autor.

Diana Sarita Hamburger

Universidade Federal do ABC

Programa de Pós-Graduação em Ciência Tecnologia Ambiental SP, Brasil e-mail: diana.sarita@ufabc.edu.br

Contribuição do autor:

Orientadora da primeira autora, participação nas coletas de campo, análise dos dados e escrita do artigo.

Tatiane Araujo de Jesus Universidade Federal do ABC Programa de Pós-Graduação em Ciência Tecnologia Ambiental e-mail: tatiane.jesus@ufabc.edu.br

Contribuição do autor:

Coorientadora da primeira autora; participação nas coletas de campo; análise dos dados e escrita do artigo.

Roseli Frederigi Benassi Universidade Federal do ABC Programa de Pós-Graduação em Ciência Tecnologia Ambiental e-mail: roseli.benassi@ufabc.edu.br

Contribuição do autor:

Participação na análise dos dados e escrita do artigo.

Valdir de Cicco Instituto Florestal do Estado de São Paulo (Pesquisador Científico) e-mail: vcicco@if.sp.gov.br

Contribuição do autor:

Participação na análise dos dados e escrita do artigo. 